\title{
Parasympathetic reactivation after maximal CPET depends on exercise modality and resting vagal activity in healthy men
}

\author{
Felipe A Cunha ${ }^{1,2}$, Adrian W Midgley ${ }^{3}$, Thiago Gonçalves ${ }^{4}$, Pedro P Soares ${ }^{4}$ and Paulo Farinatti ${ }^{2,5^{*}}$
}

\begin{abstract}
Purpose: The main purpose of this study was to investigate parasympathetic reactivation of the heart [evaluated through heart rate recovery (HRR) and HR variability (HRV)] after maximal cardiopulmonary exercise testing (CPET) using three different exercise modalities.

Methods: Twenty healthy men, aged 17 to $28 \mathrm{yr}$, performed three maximal CPETs (cycling, walking, and running) separated by $72 \mathrm{~h}$ and in a randomized, counter-balanced order. HRR was determined from the absolute differences between $H R_{\text {peak }}$ and HR at 1-3 min after exercise. The root mean square of successive R-R differences calculated for consecutive 30-s windows ( $\mathrm{rMSSD}_{30 \mathrm{~s}}$ ) was calculated to assess the parasympathetic reactivation after maximal CPET.

Results: Lower $\mathrm{HR}_{\text {peak, }} \mathrm{VO}_{2 \text { peak }}$ and energy expenditure were observed after the cycling CPET than the walking and running CPETs $(P<0.001)$. Both HRR and $\mathrm{rMSSD}_{30 \text { s }}$ were significantly greater during recovery from the cycling CPET compared to the walking and running CPETs $(P<0.001)$. Furthermore, $\Delta$ rMSSD (i.e. resting minus postexercise rMSSD every $30 \mathrm{~s}$ into the recovery period) was positively related to the resting high-frequency component (HF), rMSSD, and standard deviation of all normal R-R intervals (SDNN) ( $r_{s}=0.89$ to $0.98 ; P<0.001$ ), and negatively related to the resting low-frequency component (LF) and sympathovagal balance (LF:HF ratio) after all exercise conditions $\left(r_{s}=-0.73\right.$ to -0.79 and -0.86 to -0.90 , respectively; $\left.P<0.001\right)$.
\end{abstract}

Conclusions: These findings support that parasympathetic reactivation after maximal CPET (as assessed by HRR and $\mathrm{rMSSD}_{30 \mathrm{~s}}$ ) depends on exercise modality and cardiac autonomic control at rest.

Keywords: Autonomic nervous system; Heart rate recovery; Heart rate variability; Spectral analysis; Ergometry; Cardiopulmonary exercise testing

\section{Background}

Heart rate recovery (HRR) and heart rate variability (HRV) have emerged as noninvasive physiological markers to evaluate cardiac autonomic nervous system activity. When measured after maximal cardiopulmonary exercise testing (CPET) they are considered as powerful independent predictors of mortality in healthy subjects and in various clinical populations (Buchheit and Gindre 2006; Cole et al. 1999; Kannankeril et al. 2004; Tsuji et al. 1996). The early HRR after exercise (typically HR assessed at the $1^{\text {st }}$

\footnotetext{
*Correspondence: pfarinatti@gmail.com

${ }^{2}$ Institute of Physical Education and Sports, Laboratory of Physical Activity and Health Promotion, University of Rio de Janeiro State, Rio de Janeiro, Brazil

${ }^{5}$ Physical Activity Sciences Graduate Program, Salgado de Oliveira University, Niterói, Brazil

Full list of author information is available at the end of the article
}

min of recovery) has traditionally been used as an index of vagal activity (Pierpont et al. 2000), since its drop is a function of parasympathetic reactivation, with sympathetic withdrawal becoming more prominent later in recovery (Arai et al. 1989; Imai et al. 1994). For instance, some studies have proposed the use of HRR as a measure of autonomic dysfunction (Cole et al. 1999; Jouven et al. 2005). Another method for evaluating the autonomic modulation of HR is through HRV, which reflects beat-tobeat changes in HR, expressing the sympathovagal interaction obtained from the variation of both instantaneous HR and R-R intervals within the cardiac cycle (Task Force 1996). Most recently, it has been shown that the effect of parasympathetic drive on HRR seems to be less evident as previously believed (Buchheit et al. 2007b). Moreover, the 
time-varying analysis of HRV during exercise recovery, using the root-mean-square of the successive normal sinus $\mathrm{R}-\mathrm{R}$ interval difference calculated for consecutive 30 -s windows $\left(\mathrm{rMSSD}_{30 \mathrm{~s}}\right.$ ) to capture the instantaneous level of parasympathetic reactivation, seems to be a better tool to reflect postexercise parasympathetic reactivation (Buchheit et al. 2007a, b; Goldberger et al. 2006).

Due to their importance as clinical prognostic markers, several studies have investigated HRR and HRV after CPET performed on cycle ergometer (Danieli et al. 2014; Gaibazzi et al. 2004; Goldberger et al. 2006; Jouven et al. 2005; Ng et al. 2009) and treadmill (Buchheit and Gindre 2006; Cole et al. 1999; Dupuy et al. 2012; MorshediMeibodi et al. 2002; Vivekananthan et al. 2003). However, the HRR and HRV after maximal CPET may vary according to whether exercise is performed on treadmill or cycle ergometer, since the physiological strain induced by treadmill exercise [represented as peak $\mathrm{HR}\left(\mathrm{HR}_{\text {peak }}\right)$ and peak $\left.\mathrm{VO}_{2}\left(\mathrm{VO}_{2 \text { peak }}\right)\right]$ seems to be significantly greater than in cycle ergometer (Abrantes et al. 2012; Hill et al. 2003; Jamison et al. 2010). Only two studies have directly investigated the role of exercise modality on HRR after CPET and found faster HRR after cycle ergometry compared to treadmill exercise (Maeder et al. 2009; Rahimi et al. 2006). However, neither of these studies adopted the $\mathrm{rMSSD}_{30 \text { s }}$ index to investigate the parasympathetic reactivation after maximal CPETs. Therefore, the extent to which postexercise parasympathetic reactivation (as measured by the $\mathrm{rMSSD}_{30 \mathrm{~s}}$ index) depends on the exercise modality, remains unclear and warrants further investigation.

Another important question that has yet to be elucidated is the association between cardiac vagal modulation at rest versus parasympathetic reactivation after maximal CPET, since some studies have shown that HRR is positively correlated to resting HRV indexes (Danieli et al. 2014; Evrengul et al. 2006; Nunan et al. 2010), while others failed to find any relationship (Bosquet et al. 2007; Javorka et al. 2002). To the best of our knowledge, however, no study has investigated the relationship between resting and postexercise HRV markers (e.g. as calculated by the rMSSD $_{30 s}$ index). Therefore, the follow question remains: when the cardiac vagal activity at rest is low, would be the postexercise parasympathetic reactivation also low or there would be some dissociation?

In brief, it is unclear to what extent the exercise modality may influence the acute responses of cardiovascular autonomic control, as reflected by HRR and HRV (i.e. $\mathrm{rMSSD}_{30 \mathrm{~s}}$ ) markers. Since both cycle ergometer and treadmill exercise are frequently used in clinical exercise testing, data on the influence of exercise modality on the behavior of parasympathetic reactivation markers would be important for accurate risk prognosis. Moreover, it remains unclear the extent to which resting vagal activity of
HR is related (or not) to parasympathetic vagal reactivation represented by a faster HRR and increased $\mathrm{rMSSD}_{30 \text { s }}$.

Thus, the main purpose of the present study was to therefore investigate the effect of maximal CPET (performed using three different exercise modalities - cycling, walking, and running) and resting vagal activity on parasympathetic reactivation expressed by HRR and $\mathrm{rMSSD}_{30}$, in healthy males. We hypothesized that postexercise parasympathetic reactivation would be dependent on either exercised modality or resting vagal activity of HR.

\section{Material and methods Participants}

A group of 20 healthy men with the following characteristics volunteered for the study: mean (SD) age, 21 (3.3) yr; height, $175.1(6.3) \mathrm{cm}$; body mass, $76.1(11.2) \mathrm{kg}$; body mass index, $24.8(2.7) \mathrm{kg} / \mathrm{m}^{2}$; and body fat, 10 (5) $\%$. The participants were college students who volunteered for the study. The inclusion criteria were: a) no use of medication that might influence the cardiovascular or metabolic responses to exercise (e.g. appetite suppressant, antidepressant, antihypertensive, neuroleptics, antiarrhythmic and lithium); b) no smoking or use of ergogenic substances that could affect exercise performance; and c) absence of cardiovascular, respiratory, bone, muscle, or joint problems that could compromise the safety of physical exercise. All participants were classified as being at low risk for cardiovascular disease (ACSM 2009). The study gained approval from the University of Rio de Janeiro State (UERJ) ethics committee board and prior to the commencement of the study, participants were informed of the potential risks and discomforts, and subsequently gave written informed consent.

\section{Experimental design}

Each subject visited the laboratory four times on four separate days to undertake the following procedures:

- Visit 1. Complete a pre-participation screening questionnaire for cardiovascular risk and a questionnaire to identify aspects related to physical activity, to perform anthropometric measurements, assessment of resting HRV, and familiarization with the test protocols and equipment. All participants had previous experience with treadmill and cycle exercise and none presented difficulty, or movement limitation.

- Visits 2-4. Perform three maximal CPETs (cycling, walking, and running), separated by $72 \mathrm{~h}$ and performed in a randomized, counter-balanced order. All tests were conducted at approximately the same time of day (between 07:00 and 11:00 a.m.) to negate any effects of circadian variation. 


\section{Maximal cardiopulmonary exercise testing (CPET)}

Walking and running CPET were performed on the same motorized treadmill (Inbramed ${ }^{\text {Th }}$ Super ATL, Porto Alegre, RS, Brazil) and the cycling CPET was performed on a cycle ergometer (Cateye EC-1600, Cateye ${ }^{\mathrm{Ts}}$, Tokyo, Japan). The participants were verbally encouraged to perform a maximal effort during each CPET. The work rate increments were individualized to elicit each subject's limit of tolerance within 8-12 min. Initially, a nonexercise model developed to estimate the $\mathrm{VO}_{2}$ of a healthy population aged 19 to 80 years-old was applied (Matthews et al. 1999). Based upon the predicted maximal oxygen uptake $\left(\mathrm{VO}_{2 \max }\right)$, the final work rate was calculated using the American College of Sports Medicine (ACSM) equations for either cycling, walking, or running (ACSM 2009). For the cycling test, the mean (SD) predicted final power was $345(40) \mathrm{W}$, and $0 \mathrm{~W}$ and $30 \mathrm{~W}$ were used for the 3-min warm-up period and for the initial work rate of the incremental test, respectively. The mean work rate increment was $31 \mathrm{~W}$. The cycling cadence was maintained at $55 \mathrm{revs} \cdot \mathrm{min}^{-1}$ throughout the test.

The walking test was characterized by simultaneous changes in speed and slope. A 3-min warm-up period was performed at $5.0 \mathrm{~km} \cdot \mathrm{h}^{-1}$ and $0 \%$ grade. The initial and final treadmill speeds for the CPET were fixed at 4.0 and $6.0 \mathrm{~km} \cdot \mathrm{h}^{-1}$, respectively. The treadmill slopes for $60 \%$ and $100 \%$ of predicted $\mathrm{VO}_{2 \max }$ were then calculated, respectively, for the initial period [mean (SD) 19.5 (1.4) \%] and for the final work rate [mean (SD) 22.3 (1.5) \%]. The mean work rate increment was $0.22 \mathrm{~km} \cdot \mathrm{h}^{-1}$ for speed and $0.31 \% \cdot \mathrm{min}^{-1}$ for slope.

For the running test, the mean (SD) predicted final speed was $14.4(0.8) \mathrm{km} \cdot \mathrm{h}^{-1}$ and the work rates of $40 \%$ and $60 \%$ of the predicted $\mathrm{VO}_{2 \max }$ were then calculated, respectively, for the 3-min warm-up period [mean (SD) $5.8(0.3) \mathrm{km} \cdot \mathrm{h}^{-1}$ ] and for the initial test work rate [mean (SD) $8.6(0.5) \mathrm{km} \cdot \mathrm{h}^{-1}$ ]. The treadmill slope was set at $1 \%$ throughout the running test. The mean work rate increment was $0.6 \mathrm{~km} \cdot \mathrm{h}^{-1}$.

The tests were considered as maximal if the subjects satisfied at least three of the four following criteria: a) maximum voluntary exhaustion defined by attaining a 10 on the Borg CR-10 scale; b) $90 \%$ of the predicted $\mathrm{HR}_{\max }[220$ - age] or presence of a heart rate plateau $(\triangle \mathrm{HR}$ between two consecutive work rates $\leq 4$ beats. $\left.\min ^{-1}\right)$; c) presence of a $\mathrm{VO}_{2}$ plateau $\left(\Delta \mathrm{VO}_{2}\right.$ between two consecutive work rates of less than $\left.2.1 \mathrm{~mL} \cdot \mathrm{kg}^{-1} \cdot \mathrm{min}^{-1}\right)$; d) maximal respiratory exchange ratio $\left(\operatorname{RER}_{\max }\right)>1.10$ (Howley et al. 1995).

Breath-by-breath pulmonary gas exchanges and minute ventilation were retrospectively time-averaged into $30 \mathrm{~s}$ bins. The 30-s time averages provided a good compromise between removing noise from the $\mathrm{VO}_{2}$ data while maintaining the underlying trend (Midgley et al. 2007). Prior to testing, the gas analyzers were calibrated according to the manufacturer's instructions using a certified standard mixture of oxygen (17.01\%) and carbon dioxide $(5.00 \%)$, balanced with nitrogen $\left(\mathrm{AGA}^{\mathrm{Tx}}\right.$, Rio de Janeiro, RJ, Brazil). Flows and volumes of the pneumotacograph were calibrated with a syringe graduated for a 3 L capacity (Hans Rudolph ${ }^{\mathrm{Tw}}$, Kansas, MO, USA). The ambient temperature during all testing ranged from $21^{\circ} \mathrm{C}$ to $23^{\circ} \mathrm{C}$ and relative humidity ranged from $55 \%$ to $70 \%$.

\section{Assessment of HR and HRV}

HR and HRV were recorded by a telemetric HR monitor (RS800cx, Polar ${ }^{\mathrm{rm}}$, Kempele, Finland). The R-R intervals were downloaded by Polar Precision Performance Software (Polar ${ }^{\mathrm{rm}}$, Kempele, Finland) and averaged for each 30-s window. The sampling frequency was $1000 \mathrm{~Hz}$ and signal artifacts were filtered out by the program by excluding R-R interval values with differences of more than $30 \%$ of the preceding $\mathrm{R}-\mathrm{R}$ interval (Yamamoto et al. 1991). All the time series of $R-R$ intervals exhibited low noise (i.e. rate of erroneous $\mathrm{R}-\mathrm{R}$ intervals $\leq 5 \%$ ). For spectral analysis time series, $\mathrm{R}-\mathrm{R}$ intervals were processed by an automatic algorithm for artifact removal and were subsequently processed by Fast Fourier Transform (FFT) using Welch's method and a Hanning window with 50\% overlap, using a customized algorithm from a Matlab routine (Matlab 6.0, Mathworks Inc., USA). The beatby-beat $\mathrm{R}-\mathrm{R}$ interval series were then converted into equally spaced time series with $200 \mathrm{~ms}$ intervals using cubic spline interpolation (Task Force 1996).

Time-domain analysis consisted of measures of R-R intervals (average of all normal R-R intervals), SDNN (standard deviation of all normal R-R intervals), and rMSSD (square root of the sum of successive differences between adjacent normal R-R intervals squared). In the frequency-domain, the power spectrum density function was integrated in the two classical frequency bands, as follows: 1) low frequency band (LF: 0.04 to $0.15 \mathrm{~Hz}$ ); and 2) high frequency band (HF: 0.15 to $0.40 \mathrm{~Hz}$ ) (Task Force 1996). The HF was used as an index of vagal modulation, whereas LF was considered as representative of both sympathetic and parasympathetic nervous system influences (Cooley et al. 1998; Montano et al. 1998). The spectral values were expressed as absolute power $\left(\mathrm{ms}^{2}\right.$ ) and normalized units (n.u.) (Pagani et al. 1986). The LF:HF ratio was adopted as a marker of sympathovagal balance.

\section{Resting HRV assessment}

The subjects were instructed not to engage in any form of physical exercise in the previous $24 \mathrm{~h}$, to abstain from alcohol, soft drinks and caffeine in the $8 \mathrm{~h}$ preceding the test and to fast for $3 \mathrm{~h}$. In the laboratory, participants 
laid quietly for $10 \mathrm{~min}$ in a quiet room, kept at a relatively constant temperature $\left(21\right.$ to $23^{\circ} \mathrm{C}$ ), after which the HRV was measured for $20 \mathrm{~min}$ in the supine position. The last 10 min of data were recorded as the HRV at rest. The resting HRV was always measured at approximately the same time of the day, between 07:00 and 11:00 a.m.

\section{Determination of postexercise HRR and HRV}

Within $5 \mathrm{~s}$ after CPET cessation, participants were placed in the supine position. The HRR was assessed from the absolute differences between $\mathrm{HR}_{\text {peak }}$ and the HR values at 1-3 min after exercise (Cole et al. 1999). Apart from expression of HRR as absolute values, the relative decline in HR (e.g. $1^{\text {st }}$ to $3^{\text {rd }} \mathrm{min}$ ) were also calculated $\left(\% H R R=H R R / H R_{\text {peak }} \times 100\right)$. To assess parasympathetic reactivation in the first 3 -min after the end of each CPET, a time domain HRV vagal index (i.e. rMSSD) was calculated sequentially at each 30-s of the recovery period ( $\mathrm{rMSSD}_{30 \mathrm{~s}}$ ) (Goldberger et al. 2006).

\section{Data analysis}

Statistical analyses were completed using IBM SPSS Statistics 22 software (SPSS ${ }^{\text {тм }}$ Inc., Chicago, IL USA). Descriptive sample statistics are reported as the mean and standard deviation (SD). Differences in the maximal physiological results and heart rate for the first $3 \mathrm{~min}$ of recovery from each of the three CPET (cycling, walking, and running) were analyzed using marginal models using the Mixed procedure. The rMSSD data during the first 3 min of recovery from each CPET were time-averaged into $30 \mathrm{~s}$ bins and differences between exercise modalities and across time were analyzed using factorial marginal models. The residuals for the $\mathrm{rMSSD}_{30 \mathrm{~s}}$ marginal model were highly positively skewed, which was addressed using a $\log _{10}$ transformation of the observed data. Different covariance structures for the repeated measures residuals were assumed for the marginal models, and the best fitting covariance structure was identified as that with the lowest Hurvich and Tsai criterion value. Post hoc pairwise comparisons, with Sidakadjusted $P$ values, were used where there were significant main or interaction effects. The relationship between LF, $\mathrm{HF}$ and LF:HF ratio at rest versus $\mathrm{VO}_{2 \text { peak }}$ and versus $\Delta$ rMSSD (i.e. resting minus postexercise rMSSD) every $30 \mathrm{~s}$ into the recovery period from each CPET were analyzed using the Spearman's correlation coefficient. Two-tailed statistical significance for all null hypothesis tests was accepted as $P \leq 0.05$.

\section{Results}

Resting HRV indices are shown in Table 1. Table 2 shows the maximal physiological responses for the cycling, walking, and running CPET, and the heart rate and percentage change in heart rate at 1,2 , and $3 \mathrm{~min}$ into
Table 1 Resting heart rate variability indices $(N=20)$

\begin{tabular}{|c|c|}
\hline Variables & Mean (SD) \\
\hline \multicolumn{2}{|c|}{ Frequency domain } \\
\hline $\operatorname{LF}\left(\mathrm{ms}^{2}\right)$ & $1708(459)$ \\
\hline $\mathrm{HF}\left(m s^{2}\right)$ & $2400(1308)$ \\
\hline LF (n.u.) & $37(10)$ \\
\hline HF (n.u.) & $44(12)$ \\
\hline LF:HF ratio & $0.9(0.5)$ \\
\hline \multicolumn{2}{|l|}{ Time domain } \\
\hline R-R interval (ms) & $1013(163)$ \\
\hline SDNN (ms) & $92(39)$ \\
\hline rMSSD (ms) & $104(30)$ \\
\hline
\end{tabular}

recovery from each CPET. Significant main effects were observed for $\mathrm{VO}_{2 \text { peak }}(\mathrm{F}=11.6, P<0.001), \mathrm{HR}_{\text {peak }}$ $(\mathrm{F}=15.3, P<0.001)$, peak oxygen pulse $(\mathrm{F}=8.4, P=0.001)$, $\mathrm{RER}_{\text {max }}(\mathrm{F}=7.7, P=0.002)$, energy expenditure $(\mathrm{F}=7.4$, $P=0.001)$ and HR at the first minute of recovery $(\mathrm{F}=23.9$, $P<0.001)$. The $\mathrm{VO}_{2 \text { peak }}, \mathrm{HR}_{\text {peak, }}$, peak oxygen pulse, and energy expenditure were significantly higher in the walking and running CPET compared to the cycling CPET. Mean $\mathrm{RER}_{\max }$ was significantly higher only during treadmill walking vs. running $(P<0.001)$, while energy expenditure was significantly higher during running vs. walking $(P=0.001)$. Heart rate recovery was significantly faster for the cycling CPET than for the walking and running CPETs at 1 and 2 min into recovery, but no significant differences between exercise modalities were observed at $3 \mathrm{~min}$ into recovery.

The rMSSD $_{30 \text { s }}$ significantly increased over the first 3 min of recovery from each CPET $(\mathrm{F}=75.6, P<0.001)$ (Figure 1). Post hoc pairwise comparisons showed that each successive time point was significantly higher than the previous time point $(P \leq 0.001)$, except for the difference between 150 and $180 \mathrm{~s}(P=0.86)$. The $\mathrm{rMSSD}_{30 \mathrm{~s}}$ response during the first $3 \mathrm{~min}$ of the recovery period was affected by exercise modality $(\mathrm{F}=29.4, P<0.001)$, where $\mathrm{rMSSD}_{30 \text { s }}$ was significantly higher during the recovery from cycling compared to walking $(P<0.001)$ and running $(P<0.001)$, and significantly higher during recovery from walking compared to running $(P<0.001)$. No significant interaction between exercise modality and time was observed $(\mathrm{F}=1.7, P=0.10)$. The $\mathrm{rMSSD}_{30 \mathrm{~s}}$ at $30 \mathrm{~s}$ of recovery was significantly lower than that at rest for each of the three CPETs $(P<0.001)$.

Table 3 presents the relationships between the LF, HF, LF:HF ratio, SDNN, and rMSSD at rest vs. $\triangle$ rMSSD (i.e. resting rMSSD minus postexercise rMSSD) every $30 \mathrm{~s}$ 
Table 2 Mean (SD) maximal physiological values achieved during each of the cardiopulmonary exercise tests (CPETs) and heart rate during the first 3 min of recovery from each CPET

\begin{tabular}{|c|c|c|c|c|c|c|}
\hline & \multicolumn{3}{|c|}{ Exercise modality } & \multicolumn{3}{|l|}{$P$} \\
\hline & Cycling & Walking & Running & Cycling vs. walking & Cycling vs. running & Walking vs. running \\
\hline $\mathrm{VO}_{\text {2peak }}\left(\mathrm{ml} \cdot \mathrm{kg}^{-1} \cdot \mathrm{min}^{-1}\right)$ & $39.0(7.1)$ & $43.8(4.6)$ & $44.4(5.0)$ & 0.001 & $<0.001$ & NS \\
\hline $\mathrm{VO}_{\text {2peak }}\left(\mathrm{L} \cdot \mathrm{min}^{-1}\right)$ & $2.934(0.471)$ & $3.320(0.481)$ & $3.342(0.342)$ & $<0.001$ & $<0.001$ & NS \\
\hline EE during CPET (kcal) & $105(29)$ & $113(19)$ & $141(42)$ & 0.023 & $<0.001$ & 0.001 \\
\hline$H R_{\text {peak }}\left(\right.$ beats $\cdot \min ^{-1}$ ) & $187(10)$ & $193(9)$ & $196(9)$ & 0.003 & $<0.001$ & NS \\
\hline Oxygen pulse (beats $\cdot \mathrm{ml}^{-1}$ ) & $15.7(2.8)$ & $17.3(2.7)$ & $17.1(2.2)$ & 0.002 & 0.005 & NS \\
\hline$V_{E \max }\left(L \cdot \min ^{-1}\right)$ & $92.0(16.3)$ & $92.4(12.6)$ & $97.6(12.1)$ & NS & NS & NS \\
\hline $\mathrm{RER}_{\max }$ & $1.12(0.04)$ & $1.15(0.04)$ & $1.10(0.04)$ & NS & NS & 0.001 \\
\hline HR recovery $1^{\text {st }} \min$ (beats $\cdot \min ^{-1}$ ) & $147(11)$ & $159(13)$ & $163(12)$ & $<0.001$ & $<0.001$ & NS \\
\hline HR recovery $2^{\text {nd }}$ min (beats $\cdot \min ^{-1}$ ) & $117(13)$ & $126(13)$ & $128(11)$ & 0.001 & $<0.001$ & NS \\
\hline HR recovery $3^{\text {rd }}$ min (beats $\cdot \min ^{-1}$ ) & $108(11)$ & $112(12)$ & $114(10)$ & NS & 0.002 & NS \\
\hline$\Delta \mathrm{HR}$ recovery $1^{\mathrm{st}} \min (\%)$ & $22(3)$ & $18(4)$ & $17(4)$ & $<0.001$ & $<0.001$ & NS \\
\hline$\Delta \mathrm{HR}$ recovery $2^{\text {nd }} \min (\%)$ & $37(6)$ & $35(4)$ & $35(4)$ & 0.046 & 0.013 & NS \\
\hline$\Delta \mathrm{HR}$ recovery $3^{\text {rd }} \min (\%)$ & $42(5)$ & $42(4)$ & $42(4)$ & NS & NS & NS \\
\hline
\end{tabular}

$\mathrm{VO}_{2 \text { peak }}=$ peak oxygen uptake; $\mathrm{EE}=$ energy expenditure; $\mathrm{HR}_{\text {peak }}=$ peak heart rate; $\mathrm{V}_{\mathrm{Emax}}=$ maximal minute ventilation; $\mathrm{RER}$ max $=$ maximal respiratory exchange ratio $\mathrm{HR}=$ heart rate; $\triangle \mathrm{HR}=$ percentage difference between the peak heart rate and the heart rate at 1,2, or 3 min into the recovery period; $P=$ Sidak-adjusted $P$ value; NS $=$ not statistically significant.

into the recovery period from each CPET. Significant negative relationships were observed between the LF and LF:HF ratio at rest and $\triangle$ rMSSD within $3 \mathrm{~min}$ of recovery from each CPET $\left(r_{s}=-0.73\right.$ to -0.79 and -0.86 to -0.90 , respectively; $P<0.001)$. The $\mathrm{HF}, \mathrm{SDNN}$ and rMSSD at rest were positively correlated with $\triangle \mathrm{rMSSD}$, with Spearman's correlation coefficients $\left(r_{s}\right)$ ranging from 0.90 to $0.98(P<0.001)$ for all CPETs.

\section{Discussion}

The present study adds to current knowledge by investigating whether different exercise modalities (cycling, walking and running) and cardiac vagal activity at rest would influence parasympathetic reactivation after maximal CPETs in healthy young men. The major findings were: 1) Parasympathetic reactivation after maximal CPET (as assessed by HRR and rMSSD $_{30 s}$ ) seemed to be

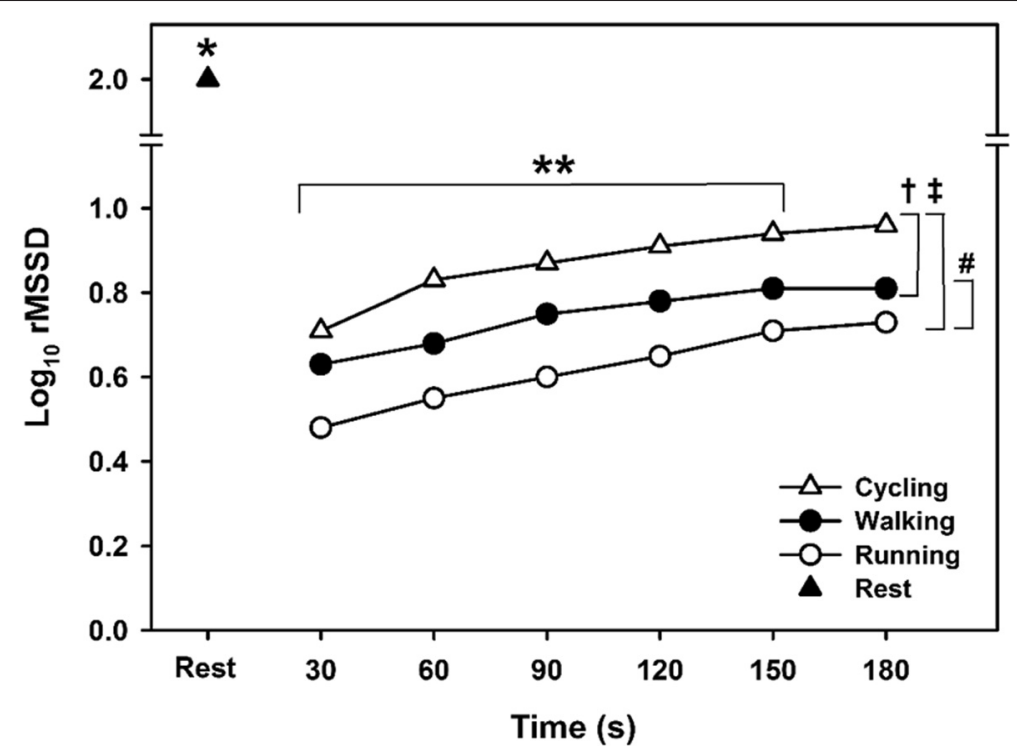

Figure 1 Mean $\log _{10}$ rMSSD at rest and during the first $3 \mathrm{~min}$ of recovery from each cardiopulmonary exercise test. Error bars have been omitted to aid clarity. ${ }^{*}$ Resting $\log _{10}$ rMSSD significantly higher than each time point during the 3 min recovery period for each cardiopulmonary exercise test $(P<0.001)$; ${ }^{* *} \log _{10}$ rMSSD at each successive time point between 30 and $150 \mathrm{~s}$ significantly higher $(P<0.001)$; † cycling vs. walking $(P<0.001)$; $\neq$ cycling vs. running $(P<0.001)$; \# walking vs. running $(P<0.001)$. 
Table 3 Relationships between $\Delta$ rMSSD vs. LF at rest, $\Delta$ rMSSD vs. HF at rest, $\Delta$ rMSSD vs. LF:HF ratio, $\Delta$ rMSSD vs. rMSSD at rest, and $\Delta$ rMSSD vs. SDNN at rest every $30 \mathrm{~s}$ into the recovery period for each of the three exercise conditions $(\mathrm{N}=\mathbf{2 0})$

\begin{tabular}{|c|c|c|c|c|c|c|c|}
\hline \multirow[t]{3}{*}{ Relationships } & \multirow[t]{3}{*}{ Exercise modality } & \multirow[b]{3}{*}{$30 \mathrm{~s}$} & \multirow{2}{*}{\multicolumn{5}{|c|}{$\begin{array}{l}\text { Spearman's correlation coefficient ( } P \text { value) } \\
\text { Exercise recovery time }\end{array}$}} \\
\hline & & & & & & & \\
\hline & & & $60 \mathrm{~s}$ & $90 \mathrm{~s}$ & $120 \mathrm{~s}$ & $150 \mathrm{~s}$ & $180 \mathrm{~s}$ \\
\hline \multirow[t]{3}{*}{$\Delta \mathrm{rMSSD}$ vs. rMSSD at rest } & Cycling & $0.92(<0.001)$ & $0.92(<0.001)$ & $0.91(<0.001)$ & $0.91(<0.001)$ & $0.91(<0.001)$ & $0.90(<0.001)$ \\
\hline & Walking & $0.94(<0.001)$ & $0.94(<0.001)$ & $0.93(<0.001)$ & $0.93(<0.001)$ & $0.93(<0.001)$ & $0.92(<0.001)$ \\
\hline & Running & $0.96(<0.001)$ & $0.96(<0.001)$ & $0.96(<0.001)$ & $0.94(<0.001)$ & $0.94(<0.001)$ & $0.92(<0.001)$ \\
\hline \multirow[t]{3}{*}{$\Delta$ rMSSD vs. SDNN at rest } & Cycling & $0.96(<0.001)$ & $0.96(<0.001)$ & $0.94(<0.001)$ & $0.91(<0.001)$ & $0.91(<0.001)$ & $0.90(<0.001)$ \\
\hline & Walking & $0.96(<0.001)$ & $0.96(<0.001)$ & $0.94(<0.001)$ & $0.94(<0.001)$ & $0.94(<0.001)$ & $0.94(<0.001)$ \\
\hline & Running & $0.98(<0.001)$ & $0.98(<0.001)$ & $0.98(<0.001)$ & $0.97(<0.001)$ & $0.97(<0.001)$ & $0.96(<0.001)$ \\
\hline \multirow[t]{3}{*}{$\Delta \mathrm{rMSSD}$ vs. HF at rest } & Cycling & $0.92(<0.001)$ & $0.91(<0.001)$ & $0.91(<0.001)$ & $0.90(<0.001)$ & $0.89(<0.001)$ & $0.90(<0.001)$ \\
\hline & Walking & $0.92(<0.001)$ & $0.91(<0.001)$ & $0.91(<0.001)$ & $0.91(<0.001)$ & $0.90(<0.001)$ & $0.92(<0.001)$ \\
\hline & Running & $0.92(<0.001)$ & $0.91(<0.001)$ & $0.91(<0.001)$ & $0.93(<0.001)$ & $0.92(<0.001)$ & $0.91(<0.001)$ \\
\hline \multirow[t]{3}{*}{$\Delta$ rMSSD vs. LF at rest } & Cycling & $-0.79(<0.001)$ & $-0.77(<0.001)$ & $-0.77(<0.001)$ & $-0.74(<0.001)$ & $-0.73(<0.001)$ & $-0.74(<0.001)$ \\
\hline & Walking & $-0.78(<0.001)$ & $-0.76(<0.001)$ & $-0.77(<0.001)$ & $-0.77(<0.001)$ & $-0.75(<0.001)$ & $-0.76(<0.001)$ \\
\hline & Running & $-0.78(<0.001)$ & $-0.79(<0.001)$ & $-0.79(<0.001)$ & $-0.78(<0.001)$ & $-0.77(<0.001)$ & $-0.77(<0.001)$ \\
\hline \multirow[t]{3}{*}{$\Delta$ rMSSD vs. LF:HF ratio at rest } & Cycling & $-0.89(<0.001)$ & $-0.88(<0.001)$ & $-0.88(<0.001)$ & $-0.87(<0.001)$ & $-0.86(<0.001)$ & $-0.87(<0.001)$ \\
\hline & Walking & $-0.88(<0.001)$ & $-0.87(<0.001)$ & $-0.88(<0.001)$ & $-0.87(<0.001)$ & $-0.87(<0.001)$ & $-0.88(<0.001)$ \\
\hline & Running & $-0.89(<0.001)$ & $-0.90(<0.001)$ & $-0.89(<0.001)$ & $-0.90(<0.001)$ & $-0.89(<0.001)$ & $-0.88(<0.001)$ \\
\hline
\end{tabular}

rMSSD = root-mean-square of the successive normal sinus R-R interval difference; SDNN = standard deviation of all normal R-R intervals; Delta $(\Delta)=$ resting rMSSD minus postexercise rMSSD; LF = high frequency component; $\mathrm{HF}=$ low frequency component; LF:HF ratio = sympathovagal balance.

dependent on either exercised modality or cardiac autonomic control at rest. Actually the HRR and change in the $\mathrm{rMSSD}_{30 \mathrm{~s}}$ index were faster for the cycling CPET (exercise involving a lower muscle mass) than for the walking and running CPETs (exercise involving a greater muscle mass); and 2) A mitigated HR response during exercise recovery was significantly correlated with a resting sympathetic activity overload (i.e. increased LF component and LF:HF ratio).

Rahimi et al. (2006) investigated the HRR from cycle ergometer and treadmill exercise in 211 individuals with known or suspected coronary artery disease. Although the treadmill exercise induced a higher $\mathrm{HR}_{\text {peak }}$, cycling presented a greater fall in HR during the early phase of recovery $(\sim 12 \%$ for treadmill vs. $\sim 16 \%$ for cycle ergometer, $P=0.004)$. Similar findings were observed by Maeder et al. (2009) who compared the HRR after maximal CPETs performed on a treadmill and cycle ergometer in 29 healthy subjects and 16 patients with chronic heart failure. For both groups, HRR obtained in the first minute was significantly faster after cycling than after treadmill exercise (health and heart failure groups: $15 \%$ and $12 \%$ for treadmill vs. $17 \%$ and $15 \%$ for cycle ergometer, respectively; $P=0.004)$. In fact, our data showed that although both treadmill exercises (walking and running) induced a higher $\mathrm{HR}_{\text {peak and }} \mathrm{VO}_{2 \text { peak }}$, cycle ergometry resulted in a faster HRR only for the first minute of recovery (18\% and 17\% for walking and running CPETs vs. $22 \%$ for cycling CPET,
$P<0.001)$, which in turn, are in agreement with the findings of previous studies (Maeder et al. 2009; Rahimi et al. 2006). Similar to HRR, the recovery of $\mathrm{rMSSD}_{30 \mathrm{~s}}$ during the first $3 \mathrm{~min}$ after CPET cessation was higher for cycling vs. walking $(P<0.001)$ and running $(P<0.001)$; but unlike HRR - where no differences were observed between walking vs. running CPETs - the parasympathetic activation by $\mathrm{rMSSD}_{30 \text { s }}$ index after walking CPET was significantly higher compared to running CPET $(P<0.001$; see Figure 1). A possible explanation for these results is that HRR mainly describes the chronotropic response in absolute values and variations between beats at maximal $H R$ and one value during recovery (i.e. reflecting a marker of parasympathetic tone), while $\mathrm{rMSSD}_{30 \mathrm{~s}}$ is basically a measure of modulation based on adjustments on beat-by-beat dynamics (Buchheit et al. 2007b; Goldberger et al. 2006). Moreover, it is important to mention that although there was no significant difference between walking and running CPETs for $\mathrm{HR}_{\text {peak }}(P=0.17)$ and $\mathrm{VO}_{2 \text { peak }}(P=0.90)$, the energy expenditure during running the CPET was significantly higher than that observed during walking CPET $(P=0.001$; see Table 2$)$.

Therefore, a question remains: what could explain the differences in postexercise parasympathetic reactivation between the three exercise modalities? Nowadays, it is widely accepted that HRR and HRV dynamics after exercise are affected mainly by exercise intensity (Lucini et al. 
2014). In the present study, maximal effort was attained in all exercise modes, but for different absolute values of $\mathrm{VO}_{2}$ and $\mathrm{HR}$ to satisfy the energy demands of working muscles (see Table 2). These differences may have influenced the underlying mechanisms of cardiodeceleration after maximal CPETs (i.e. cycling, walking and running). Although the autonomic contribution to cardiodeceleration after exercise is less understood, passive recovery from dynamic exercise is associated with the cessation of the primary exercise stimulus from the brain (i.e. central command from the cerebral motor cortex), which seems to be responsible for the early recovery phase of HR (Carter et al. 1999). Likewise, changes in the stimuli to metaboreceptors and baroreceptors accompanying clearance of metabolites and neurohumoral factors (i.e. norepinephrine, epinephrine, angiotensin, endothelin and vasopressin), or lactic acid, may contribute to HRR or HRV dynamics after exercise (Kübler 1994). For instance, findings from Hambrecht et al. (1992) showed that the physiological strain induced by cycle ergometry were associated with $20 \%$ less norepinephrine and epinephrine levels at maximal effort than treadmill exercise, despite the lower $\mathrm{HR}_{\text {peak }}$ achieved. Furthermore, the circulating plasma catecholamines at $3 \mathrm{~min}$ of recovery from cycle ergometry were significantly lower than those induced by treadmill exercise (Hambrecht et al. 1992). Although we did not measure catecholamine kinetics after exercise, it is possible that the a slower removal of accumulated metabolites (i.e. higher catecholamine levels) after the running CPET has led to a blunted parasympathetic activity and reduced sympathetic withdrawal during the early phase of recovery, which may have resulted in a delayed HRR compared to cycling and walking CPETs. For example, Miyamoto et al. (2003) showed that high levels of norepinephrine attenuate the HR response to vagal stimulation by activation of the $\alpha$-adrenergic receptors on the preganglionic and/or postganglionic cardiac vagal nerve terminals, leading to a reduced acetylcholine release in response to preganglionic vagal stimulation. Thus, our findings suggest that the effect of exercise modality on the postexercise reactivation should be taken into account for clinical applications, particularly with regard to the HR reduction during the first $30 \mathrm{~s}$ of recovery, which seems to be vagally mediated (Imai et al. 1994).

Another important finding of the present study is the influence of cardiac autonomic control at rest on the recovery pattern of HR after maximal CPET. Although the few available studies regarding the relationship between resting cardiac parasympathetic control and HRR have shown conflicting results (Bosquet et al. 2007; Danieli et al. 2014; Esco et al. 2010; Javorka et al. 2002; Nunan et al. 2010), none of these studies investigated the relationship between resting and postexercise HRV indexes. For instance, the recent findings of Duarte et al. (2014) provided evidence that adaptations to aerobic training in cardiac autonomic control at rest and during recovery from exercise present distinct dynamics. In this study, young subjects with lower and higher cardiac vagal modulation at rest underwent 12 weeks of aerobic training, and HRV at rest (i.e. HF, LF and LF:HF ratio) and parasympathetic reactivation (i.e. $\mathrm{rMSSD}_{30 \mathrm{~s}}$ ) were assessed using the same approach as in the present paper. These authors showed that subjects with lower pre-training resting HRV indices (e.g. $\downarrow$ HF and $\uparrow$ LF or LF:HF ratio, respectively) improved their autonomic profile while the ones with previous elevated vagal modulation did not. Moreover, the relationship between resting vagal modulation and postexercise vagal reactivation was observed only in subjects with baseline low levels of resting vagal control (e.g. correlation between $\Delta \% \mathrm{HF}$ vs. $\left.\Delta \% \mathrm{rMSSD}_{3-5 \min }, \mathrm{r}=0.63 ; P=0.04\right)$. On the other hand, both groups improved HRR, suggesting that the mechanisms involved in HR dynamics at rest and after exercise may not act in the same way. Resting HR oscillations depend mainly on sympathetic and vagal modulatory influences, but after maximal exercise, when parasympathetic contribution is negligible, the fast recovery is dependent on vagal reactivation with a later influence of both vagal reactivation and sympathetic withdrawal. Moreover, vagal recovery is improved with greater availability of acetylcholine by anticholinesterase inhibitor administration (Dewland et al. 2007). These are different situations, although variability still primarily depends on vagal contribution, regardless of the exercise modality. For example, Table 3 shows that all HRV indexes from spectral analysis (i.e. frequency and time domain) were significantly and strongly correlated with $\triangle \mathrm{rMSSD}$ at each $30 \mathrm{~s}$ interval during recovery. The resting parasympathetic activity (HF component), which reflects the magnitude of the fluctuation in cardiac vagal activity (Hedman et al. 1995), was positively related to $\triangle \mathrm{rMSSD}_{30-180 \mathrm{~s}}$ (i.e. $\mathrm{r}_{\mathrm{s}}$ ranging from -0.90 to $-0.93 ; P<0.001)$. On the other hand, the LF component, influenced by both sympathetic and parasympathetic discharges, and the sympathovagal balance (LF:HF ratio) were negatively related to $\Delta \mathrm{rMSSD}_{30-180 \mathrm{~s}}\left(\mathrm{r}_{\mathrm{s}}=-0.73\right.$ to -0.79 and -0.86 to -0.90 , respectively; $P<0.001$ ). Indeed, it has been suggested that a mitigated HR response to exercise is indicative of a resting sympathetic overload (Colucci et al. 1989). Nevertheless, it is noteworthy that the utility of the LF band and LF:HF ratio as only a marker of cardiac sympathetic outflow is debatable, regardless of adjustment for total power, suggesting that the LF component is also determined by cardiac parasympathetic tone (Reyes del Paso et al. 2013). However, during maneuvers that increase the adrenergic drive (i.e. like exercise stress), usually a reduction of the HF and an increase in LF is observed, suggesting a shift in the autonomic balance that may induce the concept of a predominant sympathetic origin of the LF component (Cooley et al. 1998; Montano 
et al. 1994, 1998). In addition, HRR seems to be dependent on vagal reactivation after almost total withdrawal during heavy exercise, a phenomenon distinct from vagal modulation at rest when both branches of the autonomic nervous system discharge provide the oscillatory nature of $\mathrm{HR}$ (Dewland et al. 2007; Duarte et al. 2014; Goldberger et al. 2006). Although the present findings should therefore be interpreted with caution and further experimental research is warranted to confirm this hypothesis, our data seems to support that postexercise vagal reactivation seems to be dependent on the resting cardiac vagal control (i.e. higher resting vagal modulation would result in a better chronotropic response after maximal CPET). In a clinical context, these findings have direct implications on the interpretation of the influence of exercise modality and resting vagal modulation upon HRR.

\section{Conclusion}

In conclusion, postexercise vagal reactivation (as measured by HRR and, mainly, by $\mathrm{rMSSD}_{30 \mathrm{~s}}$ ) was shown to be faster after exercise involving smaller muscle mass or energy expenditure (cycling > walking $>$ running) in healthy young men and this information should be considered in clinical settings. Moreover, postexercise parasympathetic reactivation seems to be influenced by resting vagal control, whereby subjects characterized by higher vagal modulation at rest tend to exhibit better parasympathetic reactivation and faster HRR. In a practical perspective, the resting vagal modulation appears to play a key role in postexercise parasympathetic activation, regardless of the exercise modality. These findings have direct implications on the interpretation of the influence of exercise modality and resting vagal modulation upon HRR.

\section{Abbreviations}

CPET: Cardiopulmonary exercise testing; EE: Energy expenditure; HF: Low frequency component; HR: Heart rate; HR peak: Peak heart rate; HRR: Heart rate recovery; HRV: Heart rate variability; LF: High frequency component; LF:HF ratio: Sympathovagal balance; $R E R_{\max }$ : Maximal respiratory exchange ratio; rMSSD: Root-mean-square of the successive normal sinus R-R interval difference: rMSSD ${ }_{30 \text { s: }}$ Root mean square of successive R-R differences calculated for consecutive 30-s windows; SD: Standard deviation; SDNN: Standard deviation of all normal R-R intervals; $V_{\text {Emax: }}$ : Maximal minute ventilation; $V O_{\text {2peak: }}$ : Peak oxygen uptake; $\Delta$ IMSSD: Resting rMSSD minus postexercise rMSSD.

\section{Competing interests}

The authors declare that they have no competing interests.

\section{Authors' contributions}

$\mathrm{FC}, \mathrm{AM}$, and PF were involved in the study conception, design and management, data interpretation, and drafting of the manuscript. FC was involved in the recruitment of participants, data collection and analysis, and manuscript preparation. PS and TG provided considerable intellectual input in the writing of the manuscript. PF was the principal investigator supervising all the experimental procedures and the manuscript preparation. All authors read and approved the final manuscript.

\section{Acknowledgements}

This study was partially supported by the Carlos Chagas Filho Foundation for the Research Support in Rio de Janeiro (FAPERJ, process E-26/102.545/2010 and $E-26 / 103.126 / 2011)$ and by the Brazilian Council for the Research
Development (CNPq, process 305729/2006-3 and 309012/2010-4). The authors have no conflicts of interest that are directly relevant to the content of this paper.

\section{Author details}

${ }^{1}$ Medical Sciences Graduate Program, Faculty of Medical Sciences, University of Rio de Janeiro State, Rio de Janeiro, Brazil. ${ }^{2}$ Institute of Physical Education and Sports, Laboratory of Physical Activity and Health Promotion, University of Rio de Janeiro State, Rio de Janeiro, Brazil. ${ }^{3}$ Department of Sport and Physical Activity, Edge Hill University, Ormskirk, Lancashire, UK. ${ }^{4}$ Department of Physiology and Pharmacology, Fluminense Federal University, Niterói, Rio de Janeiro, Brazil. ${ }^{5}$ Physical Activity Sciences Graduate Program, Salgado de Oliveira University, Niterói, Brazil.

Received: 29 August 2014 Accepted: 10 February 2015

Published online: 27 February 2015

\section{References}

Abrantes C, Sampaio J, Reis V, Sousa N, Duarte J (2012) Physiological responses to treadmill and cycle exercise. Int I Sports Med 33(1):26-30, doi:10.1055/s-0031-1285928

ACSM (2009) ACSM's guidelines for exercise testing and prescription, 8th edn. Lippincott Williams \& Wilkins, Baltimore

Arai Y, Saul JP, Albrecht P, Hartley LH, Lilly LS, Cohen RJ, Colucci WS (1989) Modulation of cardiac autonomic activity during and immediately after exercise. Am J Physiol 256(1 Pt 2):H132-H141

Bosquet L, Gamelin FX, Berthoin S (2007) Is aerobic endurance a determinant of cardiac autonomic regulation? Eur J Appl Physiol 100(3):363-369, doi:10.1007/s00421-007-0438-3

Buchheit M, Gindre C (2006) Cardiac parasympathetic regulation: respective associations with cardiorespiratory fitness and training load. Am J Physiol Heart Circ Physiol 291(1):H451-H458, doi:10.1152/ajpheart.00008.2006

Buchheit M, Laursen PB, Ahmaidi S (2007a) Parasympathetic reactivation after repeated sprint exercise. Am J Physiol Heart Circ Physiol 293(1):H133-H141, doi:10.1152/ajpheart.00062.2007

Buchheit M, Papelier Y, Laursen PB, Ahmaidi S (2007b) Noninvasive assessment of cardiac parasympathetic function: postexercise heart rate recovery or heart rate variability? Am J Physiol Heart Circ Physiol 293(1):H8-H10, doi:10.1152/ajpheart.00335.2007

Carter R 3rd, Watenpaugh DE, Wasmund WL, Wasmund SL, Smith ML (1999) Muscle pump and central command during recovery from exercise in humans. J Appl Physiol (1985) 87(4):1463-1469

Cole CR, Blackstone EH, Pashkow FJ, Snader CE, Lauer MS (1999) Heart-rate recovery immediately after exercise as a predictor of mortality. N Engl J Med 341(18):1351-1357, doi:10.1056/NEJM199910283411804

Colucci WS, Ribeiro JP, Rocco MB, Quigg RJ, Creager MA, Marsh JD, Gauthier DF, Hartley LH (1989) Impaired chronotropic response to exercise in patients with congestive heart failure. Role of postsynaptic beta-adrenergic desensitization. Circulation 80(2):314-323

Cooley RL, Montano N, Cogliati C, van de Borne P, Richenbacher W, Oren R, Somers VK (1998) Evidence for a central origin of the low-frequency oscillation in RR-interval variability. Circulation 98(6):556-561

Danieli A, Lusa L, Potocnik N, Meglic B, Grad A, Bajrovic FF (2014) Resting heart rate variability and heart rate recovery after submaximal exercise. Clin Auton Res 24(2):53-61, doi:10.1007/s10286-014-0225-2

Dewland TA, Androne AS, Lee FA, Lampert RJ, Katz SD (2007) Effect of acetylcholinesterase inhibition with pyridostigmine on cardiac parasympathetic function in sedentary adults and trained athletes. Am J Physiol Heart Circ Physiol 293(1):H86-H92, doi:10.1152/ajpheart.01339.2006

Duarte A, Soares PP, Pescatello L, Farinatti P (2014) Aerobic training improves vagal reactivation regardless of resting vagal control. Med Sci Sports Exerc. [Epub ahead of print]. doi:10.1249/MSS.0000000000000532

Dupuy O, Mekary S, Berryman N, Bherer L, Audiffren M, Bosquet L (2012) Reliability of heart rate measures used to assess post-exercise parasympathetic reactivation. Clin Physiol Funct Imaging 32(4):296-304, doi:10.1111/j.1475-097X.2012.01125.x

Esco MR, Olson MS, Williford HN, Blessing DL, Shannon D, Grandjean P (2010) The relationship between resting heart rate variability and heart rate recovery. Clin Auton Res 20(1):33-38, doi:10.1007/s10286-009-0033-2

Evrengul H, Tanriverdi H, Kose S, Amasyali B, Kilic A, Celik T, Turhan H (2006) The relationship between heart rate recovery and heart rate variability in 
coronary artery disease. Ann Noninvasive Electrocardiol 11(2):154-162, doi:10.1111/j.1542-474X.2006.00097.x

Gaibazzi N, Petrucci N, Ziacchi V (2004) One-minute heart rate recovery after cycloergometer exercise testing as a predictor of mortality in a large cohort of exercise test candidates: substantial differences with the treadmill-derived parameter. Ital Heart J 5(3):183-188

Goldberger JJ, Le FK, Lahiri M, Kannankeril PJ, Ng J, Kadish AH (2006) Assessment of parasympathetic reactivation after exercise. Am J Physiol Heart Circ Physiol 290(6):H2446-H2452, doi:10.1152/ajpheart.01118.2005

Hambrecht RP, Schuler GC, Muth T, Grunze MF, Marburger CT, Niebauer J, Methfessel SM, Kubler W (1992) Greater diagnostic sensitivity of treadmill versus cycle exercise testing of asymptomatic men with coronary artery disease. Am J Cardiol 70(2):141-146

Hedman AE, Hartikainen JE, Tahvanainen KU, Hakumaki MO (1995) The high frequency component of heart rate variability reflects cardiac parasympathetic modulation rather than parasympathetic 'tone'. Acta Physiol Scand 155(3):267-273

Hill DW, Halcomb JN, Stevens EC (2003) Oxygen uptake kinetics during severe intensity running and cycling. Eur J Appl Physiol 89(6):612-618, doi:10.1007/s00421-002-0779-x

Howley ET, Bassett DR Jr, Welch HG (1995) Criteria for maximal oxygen uptake: review and commentary. Med Sci Sports Exerc 27(9):1292-1301

Imai K, Sato H, Hori M, Kusuoka H, Ozaki H, Yokoyama H, Takeda H, Inoue M, Kamada T (1994) Vagally mediated heart rate recovery after exercise is accelerated in athletes but blunted in patients with chronic heart failure. J Am Coll Cardiol 24(6):1529-1535, doi:0735-1097(94)90150-3

Jamison JP, Megarry J, Riley M (2010) Exponential protocols for cardiopulmonary exercise testing on treadmill and cycle ergometer. Eur J Appl Physiol 108(1):167-175, doi:10.1007/s00421-009-1183-6

Javorka M, Zila I, Balharek T, Javorka K (2002) Heart rate recovery after exercise: relations to heart rate variability and complexity. Braz J Med Biol Res 35(8):991-1000, doi:S0100-879X2002000800018

Jouven X, Empana JP, Schwartz PJ, Desnos M, Courbon D, Ducimetiere P (2005) Heart-rate profile during exercise as a predictor of sudden death. $\mathrm{N}$ Engl J Med 352(19):1951-1958, doi:10.1056/NEJMoa043012

Kannankeril PJ, Le FK, Kadish AH, Goldberger JJ (2004) Parasympathetic effects on heart rate recovery after exercise. J Investig Med 52(6):394-401

Kübler W (1994) Human cardiovascular control: Edited by Loring B. Rowell, Oxford University Press, New York (1993) 500 pages illustrated \$65.00 ISBN: 9-19-507362-2. Clin Cardiol 17(2):98, doi:10.1002/clc.4960170212

Lucini D, Vigo C, Tosi F, Toninelli G, Badilini F, Pagani M (2014) Assessing autonomic response to repeated bouts of exercise below and above respiratory threshold: insight from dynamic analysis of RR variability. Eur J Appl Physiol 114(6):1269-1279, doi:10.1007/s00421-014-2858-1

Maeder MT, Ammann P, Rickli H, Brunner-La Rocca HP (2009) Impact of the exercise mode on heart rate recovery after maximal exercise. Eur J Appl Physiol 105(2):247-255, doi:10.1007/s00421-008-0896-2

Matthews CE, Heil DP, Freedson PS, Pastides H (1999) Classification of cardiorespiratory fitness without exercise testing. Med Sci Sports Exerc 31(3):486-493

Midgley AW, McNaughton LR, Carroll S (2007) Effect of the VO2 time-averaging interval on the reproducibility of VO2max in healthy athletic subjects. Clin Physiol Funct Imaging 27(2):122-125, doi:10.1111/j.1475-097X.2007.00725.X

Miyamoto T, Kawada T, Takaki H, Inagaki M, Yanagiya Y, Jin Y, Sugimachi M, Sunagawa K (2003) High plasma norepinephrine attenuates the dynamic heart rate response to vagal stimulation. Am J Physiol Heart Circ Physiol 284(6):H2412-H2418, doi:10.1152/ajpheart.00660.2002

Montano N, Ruscone TG, Porta A, Lombardi F, Pagani M, Malliani A (1994) Power spectrum analysis of heart rate variability to assess the changes in sympathovagal balance during graded orthostatic tilt. Circulation 90(4):1826-1831

Montano N, Cogliati C, Porta A, Pagani M, Malliani A, Narkiewicz K, Abboud FM, Birkett C, Somers VK (1998) Central vagotonic effects of atropine modulate spectral oscillations of sympathetic nerve activity. Circulation 98(14):1394-1399

Morshedi-Meibodi A, Larson MG, Levy D, O'Donnell CJ, Vasan RS (2002) Heart rate recovery after treadmill exercise testing and risk of cardiovascular disease events (The Framingham Heart Study). Am J Cardiol 90(8):848-852, doi:S0002914902027066
Ng J, Sundaram S, Kadish AH, Goldberger JJ (2009) Autonomic effects on the spectral analysis of heart rate variability after exercise. Am J Physiol Heart Circ Physiol 297(4):H1421-H1428, doi:10.1152/ajpheart.00217.2009

Nunan D, Jakovljevic DG, Donovan G, Singleton LD, Sandercock GR, Brodie DA (2010) Resting autonomic modulations and the heart rate response to exercise. Clin Auton Res 20(4):213-221, doi:10.1007/s10286-010-0073-7

Pagani M, Lombardi F, Guzzetti S, Rimoldi O, Furlan R, Pizzinelli P, Sandrone G, Malfatto G, Dell'Orto S, Piccaluga E et al (1986) Power spectral analysis of heart rate and arterial pressure variabilities as a marker of sympatho-vagal interaction in man and conscious dog. Circ Res 59(2):178-193

Pierpont GL, Stolpman DR, Gornick CC (2000) Heart rate recovery post-exercise as an index of parasympathetic activity. J Auton Nerv Syst 80(3):169-174

Rahimi K, Thomas A, Adam M, Hayerizadeh BF, Schuler G, Secknus MA (2006) Implications of exercise test modality on modern prognostic markers in patients with known or suspected coronary artery disease: treadmill versus bicycle. Eur J Cardiovasc Prev Rehabil 13(1):45-50, doi:00149831-200602000-00007

Reyes del Paso GA, Langewitz W, Mulder L, van Roon A, Duschek S (2013) The utility of low frequency heart rate variability as an index of sympathetic cardiac tone: a review with emphasis on a reanalysis of previous studies. Psychophysiology 50(5):477-487, doi:10.1111/psyp.12027

Task Force (1996) Heart rate variability: standards of measurement, physiological interpretation and clinical use. Task Force of the European Society of Cardiology and the North American Society of Pacing and Electrophysiology. Circulation 93(5):1043-1065

Tsuji H, Larson MG, Venditti FJ Jr, Manders ES, Evans JC, Feldman CL, Levy D (1996) Impact of reduced heart rate variability on risk for cardiac events. The Framingham Heart Study. Circulation 94(11):2850-2855

Vivekananthan DP, Blackstone EH, Pothier CE, Lauer MS (2003) Heart rate recovery after exercise is a predictor of mortality, independent of the angiographic severity of coronary disease. J Am Coll Cardiol 42(5):831-838, doi:S0735109703008337

Yamamoto Y, Hughson RL, Peterson JC (1991) Autonomic control of heart rate during exercise studied by heart rate variability spectral analysis. J Appl Physiol 71(3):1136-1142

\section{Submit your manuscript to a SpringerOpen ${ }^{\odot}$ journal and benefit from:}

- Convenient online submission

- Rigorous peer review

- Immediate publication on acceptance

- Open access: articles freely available online

- High visibility within the field

- Retaining the copyright to your article

Submit your next manuscript at $>$ springeropen.com 